\title{
LTP Allergy Follow-Up Study: Development of Allergy to New Plant Foods 10 Years Later
}

\author{
Diana Betancor ${ }^{1}$, Alicia Gomez-Lopez ${ }^{1}$, Carlos Villalobos-Vilda ${ }^{1}$, Emilio Nuñez-Borque ${ }^{2}$, \\ Sergio Fernández-Bravo ${ }^{2}$, Manuel De las Heras Gozalo ${ }^{1,3}$, Carlos Pastor-Vargas 3,4,*(D), Vanesa Esteban 2,3,5,+(D) \\ and Javier Cuesta-Herranz $1,3,+$
}

1 Department of Allergy, Instituto de Investigación Sanitaria Hospital Universitario Fundación Jiménez Díaz (IIS-FJD, UAM), 28040 Madrid, Spain; diana13_b@hotmail.com (D.B.); alicia.gomezl@quironsalud.es (A.G.-L.); c.villalobosvilda@gmail.com (C.V.-V.); mheras@fjd.es (M.D.l.H.G.); j.cuestaherranz@gmail.com (J.C.-H.)

2 Department of Immunology, Instituto de Investigación Sanitaria Hospital Universitario Fundación Jiménez Díaz (IIS-FJD, UAM), 28040 Madrid, Spain; enbli7@hotmail.com (E.N.-B.); sergio.fernandezb@quironsalud.es (S.F.-B.); vesteban@fjd.es (V.E.)

3 RETIC ARADyAL, Instituto de Salud Carlos III, 28029 Madrid, Spain

4 Department of Biochemistry and Molecular Biology, Universidad Complutense de Madrid, 28040 Madrid, Spain

5 Faculty of Medicine and Biomedicine, Alfonso X El Sabio University, Villanueva de la Cañada, 28691 Madrid, Spain

check for updates

Citation: Betancor, D.; Gomez-Lopez, A.; Villalobos-Vilda, C.;

Nuñez-Borque, E.; Fernández-Bravo, S.; De las Heras Gozalo, M.; Pastor-Vargas, C.; Esteban, V.; Cuesta-Herranz, J. LTP Allergy Follow-Up Study: Development of Allergy to New Plant Foods 10 Years Later. Nutrients 2021, 13, 2165. https://doi.org/10.3390/nu13072165

Academic Editors: Sara Manti, Gian Luigi Marseglia and Salvatore Leonardi

Received: 15 May 2021

Accepted: 22 June 2021

Published: 24 June 2021

Publisher's Note: MDPI stays neutral with regard to jurisdictional claims in published maps and institutional affiliations.

Copyright: (c) 2021 by the authors. Licensee MDPI, Basel, Switzerland. This article is an open access article distributed under the terms and conditions of the Creative Commons Attribution (CC BY) license (https:// creativecommons.org/licenses/by/ $4.0 /)$.
* Correspondence: cpasto01@ucm.es

+ These authors have contributed equally to this work.

Abstract: Introduction: Allergy to nonspecific lipid transfer protein (nsLTP) is the main cause of plant-food allergy in Spain. nsLTPs are widely distributed in the plant kingdom and have high crossreactivity but extremely variable clinical expression. Little is known about the natural evolution of this allergy, which complicates management. The objective of this study was to assess the development of allergy to new plant foods in nsLTP-sensitized patients 10 years after diagnosis. Methods: One hundred fifty-one patients showing specific IgE to nsLTP determined by ISAC (Thermofisher) were included. After clinical workup (i.e., anamnesis, skin test, and challenge when needed), these patients were divided into two groups: 113 patients allergic to one or more plant food $(74.5 \%)$ and 38 patients not allergic to any plant food (25.1\%). Ten years later, a telephone interview was conducted to check whether patients had developed additional allergic reactions to plant foods. Results: Ten years after diagnosis, 35 of the 113 (31\%) plant-food-allergic patients sensitized to nsLTP reported reactions to new, previously tolerated plant foods, mainly Rosaceae / Prunoideae fruits and nuts followed by vegetables, Rosacea/Pomoideae fruits, legumes, and cereals. Five out of 38 (13.2\%) patients previously sensitized to nsLTP but without allergy to any plant food had experienced allergic reactions to some plant food: two to Rosaceae/Prunoideae fruits, two to Rosaceae/Prunoideae fruit and nuts, and one to legumes. Conclusion: Patients sensitized to nsLTP developed allergic reactions to other plant foods, mainly Rosaceae-Prunoideae fruits and nuts. This was more frequent among plant-food-allergic patients than among those who had never had plant-food allergy.

Keywords: nsLTP; plant-food allergy; Pru p 3; peach; nut; Rosaceae fruit; ISAC

\section{Introduction}

Food allergy affects around $0.3 \%$ to $5.6 \%$ of the population, showing substantial geographical variation in prevalence and in terms of the culprit food [1]. Allergy to plant foods is the most common food allergy among older children and adults [1].

Nonspecific lipid transfer proteins (nsLTPs) are small, highly stable and conserved molecules involved in the plant defense against fungi and bacteria [2,3]. nsLTPs are found in high concentrations in the epidermal tissues of fruits and are the main allergens of fruits 
of the Rosaceae family. In addition, allergenic nsLTPs have been found in nuts, seeds, vegetables, pollen, and latex from Hevea brasiliensis [4]. Allergy to nsLTP involves several taxonomically unrelated plant-derived foods and heterogeneous sensitization profiles and can trigger severe systemic reactions. It has been reported to be responsible for a large number of plant-food-induced anaphylactic reactions in southern Europe [5-8].

Fruits of the Rosaceae family are the most frequently involved foods in allergic reactions among nsLTP-allergic patients [9]. Allergy to nsLTP occurs predominantly in the Mediterranean area (Spain, Italy, etc.) [5,6], although it has also been reported in other areas such as Australia [10] and China [11]; in contrast, nsLTP allergy is a rare finding in northern and central Europe [7,12] and the USA [5].

Patients with allergy to nsLTP exhibit considerable clinical heterogeneity, as some react to only one food (often peach), while others may experience symptoms to multiple nsLTPs from allergenic sources that are not taxonomically related and do not follow a defined pattern [13]. The extreme variability of nsLTP allergy in terms of the culprit plant food and the clinical expression of the allergy is still unexplained. Strict plant-food avoidance diets are sometimes recommended due to the unknown clinical course, though these measures have a significant negative impact on patients' quality of life and nutrition. Little is known about the natural evolution of this syndrome.

The management of patients allergic to nsLTP is complex and poses a major challenge for both allergists and patients. The problem lies in the fact that LTP is a panallergen, meaning that it is a ubiquitous protein that is widely distributed in plant foods and has wide cross-reactivity and a highly variable clinical expression, sometimes eliciting lifethreatening reactions. Further complicating this situation is the possibility that patients sensitized to homologous nsLTPs of other plant foods can progress over time from mere sensitization (without clinical expression) to severe or even fatal allergic reactions, which has clear implications for the dietary recommendations given to nsLTP-allergic patients.

On the other hand, the LEAP study revealed that early food introduction can prevent the onset of allergy [14], the STOP study showed that induction of tolerance can halt allergy [15], and Pru p 3 SLIT induces an improvement not only in peach allergy but also acts upon other relevant food allergens causing severe reactions, such as peanut or tree nuts [16-18]. These facts could also have important implications for dietary recommendations for LTP-allergic patients. In this respect, intake of plant foods containing cross-reactive proteins that the patient tolerates and to which he/she is sensitized might improve LTP allergy in the future.

The management of such patient heterogeneity continues to challenge the expertise of allergists despite the study by Asero et al. [19] and the recommendations given by the EAACI Task Force on nsLTP Allergy Across Europe [4].

The aim of this study was to assess the development of allergy to new plant foods in nsLTP-sensitized patients over 10 years. The results reinforce key points that inform decision-making related to the management of this heterogenous and complex type of allergy.

\section{Materials and Methods}

\subsection{Study Design}

One hundred fifty-one out of 164 patients sensitized to nsLTP as determined by ImmunoCAP TM ISAC (Thermo Fisher Scientific, Uppsala, Sweden) performed during 2009-2011 in the allergy department of Fundación Jiménez Díaz (Madrid, Spain) were included in the study. Thirteen patients $(7.9 \%)$ were excluded because they did not respond to the follow-up phone call, refused to answer, or did not give consent to participate in the study. After a clinical study (2009-2011) in real-life conditions (i.e., anamnesis, skin test or specific IgE and challenge test when needed), patients were divided into 2 groups: 113 patients allergic to plant food $(74.8 \%)$ and 38 non-food-allergic patients $(25.1 \%)$. Once a patient was diagnosed with an allergy to a plant food, they were advised to avoid the food in question and continue eating those they tolerated. Ten years later, in 2020-2021, 
a telephone interview was conducted to determine whether the patients had developed new allergic reactions to previously tolerated plant foods (Figure 1).

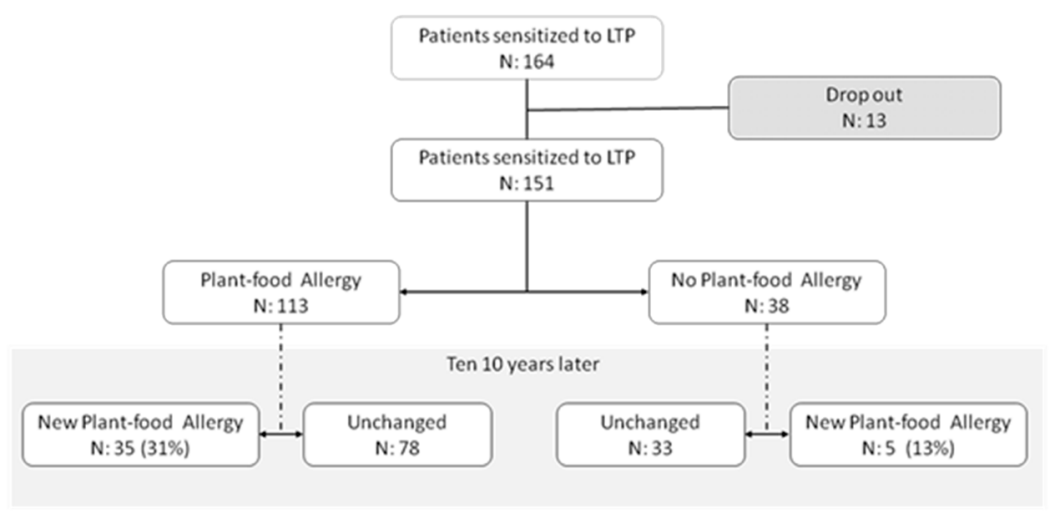

Figure 1. Study flow chart.

\subsection{Specific IgE to LTP}

All patients showed specific IgE to at least one nsLTP (Pru p 3, Cor a 8, Art v 3 before 2011 and Pru p 3, Cor a 8, Art v 3, Ara h 9, Jug r 3, Ole e 7, Pla a 3 after 2011) measured by ImmunoCAPTM ISAC following manufacturer recommendations. Results were expressed in ISU (ISAC standardized units).

\subsection{Study Variables}

On the one hand, data were collected at the time of diagnosis, including demographic and clinical characteristics of the patients; sensitization to common allergens (defined as at least 1 positive skin prick test or serum-specific IgE to common allergens); associated rhinitis or asthma; specific IgE to different nsLTPs, profilins, and PR-10 proteins as determined by ImmunoCAP ${ }^{\mathrm{TM}}$ ISAC microarray; and data related to plant-food allergy such as the plant food eliciting allergy and symptoms of the reactions, which were categorized into local symptoms, systemic symptoms, and anaphylaxis (two or more organs involved).

On the other hand, after the telephone interview, data collected at the time of diagnosis were re-evaluated to distinguish those patients who had developed allergy to nsLTP-related foods during follow-up so as to search for characteristics that could predict progression to allergy in nsLTP syndrome.

\section{Statistical Analysis}

Statistical analysis was performed with SPSS (SPSS Inc., Chicago, IL, USA). Qualitative variables were expressed as percentages and confidence intervals were calculated at $95 \%$. For quantitative variables, means and standard deviation (SD) were calculated, and for specific IgE results, medians and 25th $(\mathrm{Q} 1)$ and 75 th $(\mathrm{Q} 3)$ percentiles were given. $\mathrm{A} \chi^{2}$ test was used to compare frequencies. Values were considered significant at a $p$-value of less than 0.05 .

\section{Results}

\subsection{Patient Characteristics}

One hundred fifty-one patients sensitized to nsLTP were selected and analyzed for this study. Thirty-eight patients were asymptomatic upon nsLTP-related food exposure and 113 patients were allergic to nsLTP-related plant foods. Characteristics of the patients are shown in Table 1. 
Table 1. Demographic and clinical characteristics of patients sensitized to nsLTP (baseline data).

\begin{tabular}{|c|c|c|}
\hline & Food Allergy & Non-Food-Allergy \\
\hline & Group (n:113) & Group (n:38) \\
\hline Sex, male & $59(52.21 \%)$ & $23(60.52 \%)$ \\
\hline Age (years) (mean, SD) & $31.67(14.36)$ & $30.87(12.5)$ \\
\hline Previous atopy 1 history & $94(83.18 \%)$ & $28(73.68 \%)$ \\
\hline Allergic rhinitis & $92(81.41 \%)$ & $29(76.32 \%)$ \\
\hline Asthma & $58(51.32 \%)$ & $18(47.37 \%)$ \\
\hline $\begin{array}{c}\text { Sensitization to common } \\
\text { allergens }\end{array}$ & $102(90.26 \%)$ & $35(92.10 \%)$ \\
\hline Pollen sensitization & $101(89.38 \%)$ & $34(89.47 \%)$ \\
\hline Grass & $92(81.41 \%)$ & $29(76.31 \%)$ \\
\hline Olive & $64(56.64 \%)$ & $20(52.63 \%)$ \\
\hline Cypress & $58(51.33 \%)$ & $18(47.36 \%)$ \\
\hline Platanus tree & $65(57.52 \%)$ & $19(50.00 \%)$ \\
\hline Mugwort & $72(63.72 \%)$ & 15 (39.47\%) \\
\hline Animal sensitization & $47(41.59 \%)$ & $22(57.89 \%)$ \\
\hline Dust mite sensitization & $28(24.77 \%)$ & $11(28.95 \%)$ \\
\hline Mold sensitization & $21(18.58 \%)$ & $8(21.05 \%)$ \\
\hline Grass pollen immunotherapy & $58(51.33 \%)$ & $24(63.16 \%)$ \\
\hline Panallergen sensitization & $71(62.83 \%)$ & $22(57.89 \%)$ \\
\hline Profilin & $38(33.63 \%)$ & $9(23.68 \%)$ \\
\hline Bet $\mathrm{v} 1$ & $19(16.81 \%)$ & $10(26.32 \%)$ \\
\hline
\end{tabular}

\subsubsection{Plant-Food-Allergy Group (Baseline Data)}

One hundred thirteen patients sensitized to nsLTP were allergic to plant food before the start of the follow-up period. Characteristics of the patients are shown in Table 1.

The frequency of sensitization to different nsLTPs (ISAC) at the beginning of the study was as follows: $87.6 \%$ to Pru p 3 ( $n=99$ out 113 patients tested), with a median positive test value of 3.3 ISU (1.15-5.5 Q1-Q3); $80.6 \%$ to Pla a $3(n=29 / 36)$, median 0.8 ISU $(0.6-2.2)$; $75.9 \%$ to Jug r $3(n=23 / 29)$, median 1 ISU $(0.55-1.75) ; 64.3 \%$ to Art v $3(n=72 / 112)$, median 1.6 ISU (0.6-3.2); 53.1\% to Cor a 8 in $(n=59 / 111)$, median 1.3 ISU $(0.7-3.13) ; 59.3 \%$ to Ara $h$ $9(n=16 / 27), 0.9$ ISU $(0.5-1.6)$; and $30.8 \%$ to Ole e $7(n=8 / 26)$, median 1.3 ISU $(0.4-2.3)$. These results are shown in Figure 2.

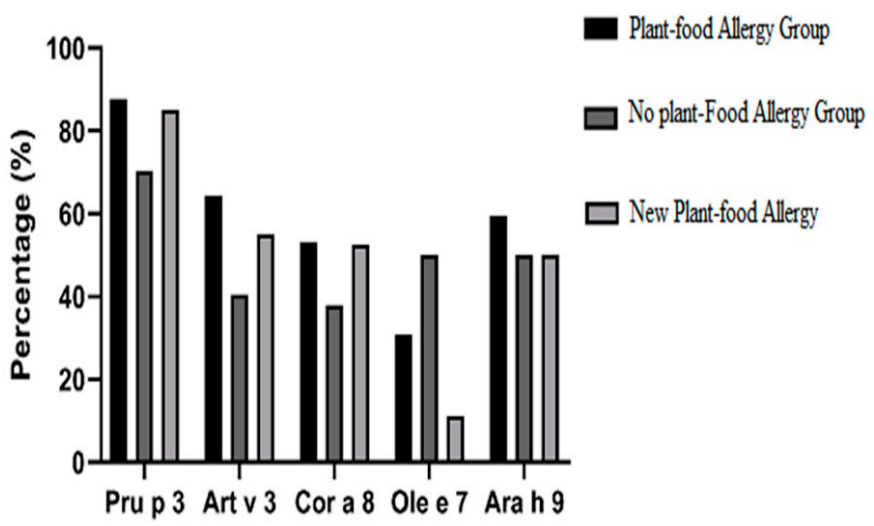

Figure 2. Percentage of sensitization to several nsLTPs in different groups of patients. 
Foods eliciting allergy in this patient group are listed in Table 2. Peach and nut were the most frequently involved plant foods (70 and 54 patients, respectively) followed by apple (37 patients) and hazelnut and peanut (36 patients in both). Cofactors were associated in 11 patients $(9.7 \%)$, 4 of whom had anaphylaxis.

Table 2. Plant foods involved in the allergic reactions of nsLTP allergy group $(n=113)$ at baseline. Results are shown in number of patients.

\begin{tabular}{|c|c|c|c|}
\hline Plant Food & Food Allergy & Oral Tolerance & Not Known \\
\hline Nuts & 77 & 30 & 6 \\
\hline Walnut & 54 & 21 & 38 \\
\hline Hazelnut & 36 & 41 & 36 \\
\hline Peanut & 36 & 41 & 36 \\
\hline Almond & 29 & 48 & 36 \\
\hline Sunflower seed & 15 & 55 & 43 \\
\hline Fruits & 95 & 18 & 0 \\
\hline \multicolumn{4}{|l|}{ Rosaceae fruits } \\
\hline Peach & 70 & 37 & 6 \\
\hline Peach (peel only) & 35 & 37 & 41 \\
\hline Apricot & 22 & 42 & 49 \\
\hline Cherry & 18 & 45 & 50 \\
\hline Strawberry & 8 & 58 & 47 \\
\hline Plum & 20 & 46 & 47 \\
\hline \multicolumn{4}{|l|}{ Pomoideae fruits } \\
\hline Apple & 37 & 50 & 26 \\
\hline Apple (peel only) & 54 & 50 & 9 \\
\hline 11 Pear & 15 & 90 & 8 \\
\hline \multicolumn{4}{|l|}{ Other fruits } \\
\hline Kiwi & 18 & 67 & 28 \\
\hline Banana & 11 & 67 & 35 \\
\hline Legumes & 12 & 78 & 23 \\
\hline Lentil & 7 & 95 & 11 \\
\hline Bean & 4 & 80 & 29 \\
\hline Soybean & 2 & 109 & 2 \\
\hline Chickpea & 1 & 100 & 12 \\
\hline Vegetables & 23 & 89 & 1 \\
\hline Tomato & 12 & 99 & 2 \\
\hline Lettuce and derivates & 10 & 84 & 19 \\
\hline Corn & 3 & 91 & 19 \\
\hline Eggplant & 2 & 78 & 35 \\
\hline Cauliflower & 2 & 65 & 46 \\
\hline Seed & 9 & 64 & 40 \\
\hline Mustard & 8 & 54 & 51 \\
\hline Sesame & 1 & 69 & 43 \\
\hline Cereal (Wheat) & 2 & 111 & 0 \\
\hline
\end{tabular}

Eighty-five patients (75.2\%) developed systemic symptoms, 23 of whom (20\%) experienced an anaphylactic reaction. The plant foods responsible for the anaphylactic reactions were as follows: nuts (39.1\%), Rosacea / Prunoideae fruits (21.7\%), Rosacea / Pomoideae fruits $(17.4 \%)$, lettuce $(13.0 \%)$, and legumes $(8.7 \%)$. Sensitization to profilin in this anaphylaxis subgroup was $26 \%$ (6 patients) and 30.4\% were sensitized to PR-10 (7 patients). The rate of anaphylaxis in profilin-sensitized patients was $7.8 \%$, and $22 \%$ of profilin-negative patients presented anaphylaxis. 


\subsubsection{Non-Food-Allergy Group (Baseline Data)}

At the start of the study, 38 out of 151 patients sensitized to any nsLTP had not experienced any plant-food allergy. These patients made up the group of non-plant-foodallergic patients. Characteristics of the patients are shown in Table 1.

The most common allergens identified through specific IgE (ISAC) were the following: Pru p 3 in 70.3\% (26/37) of patients, median 1.85 ISU (0.8-3.4); Art v 3 in 40.5\% (15/37), median value 0.8 ISU (0.6-1.45); Cor a 8 in $37.84 \%$ (14/37), 1.05 ISU (0.6-1.4). These results are shown in Figure 2.

There was no statistically significant difference in specific IgE to different nsLTPS between the 2 groups (nsLTPS-allergy group and the non-food-allergy group). However, there was a statistically significant difference between the percentage of positive patients between the 2 groups to Pru p $3(p=0.012)$ and Art v $3(p=0.013)$, but not to Ara h 9, Cor a 8, Jug r 3, Ole e 7, and Pla a 3. Comparisons are shown in Figure 2.

\subsection{Characteristics of Patients Not Sensitized to Pru $\mathrm{p} 3$}

Twenty-five of 156 patients had negative specific IgE to Pru $\mathrm{p}$ 3: 14/113 patients (12.4\%) from the plant-food-allergy group and $11 / 38$ patients $(28.9 \%)$ from the group without food allergy.

Focusing on the plant-food-allergy group, 5 out of $14(20 \%)$ patients had a systemic reaction, one of which (4\%) was an anaphylactic reaction. Despite the negative value for Pru p 3, 9 patients had allergy-related symptoms to peach. Sensitization to nsLTP among Pru p 3-negative patients was as follows: 7 patients (50\%) monosensitized to Art v 3, 2 patients to Pla a 3, 1 patient to Cor a 8, and 1 patient to Ara h 9. The other 3 patients were polysensitized with Art $v 3$ involved in all cases: 1 patient to Cor a 8 and Art v 3, 1 patient to Jug r 3 and Art v 3, and 1 patient to Ara h 9, Jug r 3, Art v 3, and Pla a 3. These results are shown in Table 3.

Table 3. Characteristics of patients non-sensitized to Pru p $3(n=25)$.

\begin{tabular}{ccc}
\hline & $\begin{array}{c}\text { Plant-Food-Allergy Group } \\
(\boldsymbol{n}=\mathbf{1 4})\end{array}$ & $\begin{array}{c}\text { Non-Plant-Food-Allergy Group } \\
(\boldsymbol{n}=\mathbf{1 1})\end{array}$ \\
\hline Sensitization to nsLTP & $7(50 \%)$ & $6(54.54 \%)$ \\
\hline Art v 3 & $1(7.14 \%)$ & $0(0 \%)$ \\
\hline Ara h 9 & $1(7.14 \%)$ & $3(27.27 \%)$ \\
\hline Cor a 8 & $2(14.28 \%)$ & $0(0 \%)$ \\
\hline Pla a 3 & $0(0 \%)$ & $1(9.09 \%)$ \\
\hline Jug r 3 & $1(7.14 \%)$ & $0(0 \%)$ \\
\hline Cor a 8 + Art v 3 & $1(7.14 \%)$ & $0(0 \%)$ \\
\hline Jug r 3 + Art v 3 & $1(7.14 \%)$ & $1(9.1 \%)$ \\
\hline $\begin{array}{c}\text { Ara h 9 + Jug r 3 + Art v 3+ } \\
\text { Pla a 3 }\end{array}$ & $2(18.2 \%)$ \\
\hline Panallergen sensitization & $6(42.9 \%)$ & $1(9.1 \%)$ \\
\hline Profilin & $3(21.4 \%)$ & \\
\hline PR10 & $5(35.7 \%)$ & \\
\hline $\begin{array}{c}\text { Allergy to new plant food } \\
\text { (clinical progression) }\end{array}$ & & \\
\hline
\end{tabular}

Nine patients non-sensitized to Pru p 3 were positive for other panallergens: 6 to profilin and 3 to the PR-10 protein family.

In the group without food allergy, 5 patients (55.4\%) were monosensitized to Art v 3, 3 patients to Cor a 8 , and 1 patient to Jug $\mathrm{r} 3$. The other patient was sensitized to both Cor a 8 and Art v 3 . 
Three patients were sensitized to other panallergens: 2 patients to allergens belonging to the PR-10 protein family and 1 patient to profilin.

\subsection{Follow-Up Study: Allergy to New Plant Foods over the Years}

Forty out of 151 patients sensitized to nsLTP (26.5\%; 95\% CI 20-34\%) developed symptoms of allergy to new (previously tolerated) plant foods during the follow-up period. Patients in this group had a mean age of 31.4 years (range 2 to 62 years) with a higher prevalence of female patients $(60 \%)$. In addition, $95 \%$ of patients had a history of atopy and $90.2 \%$ had current atopy.

The frequency of sensitization to different nsLTPs (ISAC) at the beginning of the study was as follows: $85 \%$ of 40 patients were sensitized to Pru p 3, with a median value of 2.4 ISU (1.04-4.7 Q1-Q3); $50 \%$ of 10 patients to Ara h 9, median 0.9 ISU (0.4-1); $52.5 \%$ of 40 patients to Cor a 8, median 1.2 ISU (0.6-0.8); 72.7\% of 11 patients to Jug $\mathrm{r} 3$, median 1 ISU (0.9-2.8); $55 \%$ of 40 patients to Art v 3, median 1.2 ISU (0.6-2.1); $77 \%$ of 13 patients to Pla a 3, mv 1.56 ISU (0.6-2.3); and $11.1 \%$ to ole e 7 (one patient). There was no statistical difference in the specific IgE rate to different LTPs between the group of patients that developed allergy to new plant foods or not (Figure 2). In addition to nsLTP sensitization, 8 patients $(20 \%)$ that developed allergy to new plant foods were also sensitized to PR-10 and 9 patients $(22.5 \%)$ to profilin.

\subsubsection{Plant-Food-Allergy Group: Allergy to New Foods}

Thirty-five (31\%; $95 \%$ CI $23-40 \%$ ) of the 113 patients from the plant-food-allergy group developed allergy to new plant foods: 16 patients to Rosaceae fruits (13 to Rosaceae / Prunoideae fruits and 3 to Rosaceae / Pomoideae fruits), 16 to nuts (5 patients shared Rosaceae fruits and nuts), 4 patients to vegetables, 2 to cereals, 1 to legumes, and 1 to seeds. The allergy symptoms in these patients were local reactions in $37.1 \%$ and systemic reactions in $62.9 \%$; $8.6 \%$ (of the total) were anaphylactic reactions. All new plant foods that elicited allergic reactions during the follow-up period are shown in Table 4.

Table 4. Allergy to new plant foods on follow-up study in patients sensitized to nsLTP.

\begin{tabular}{ccc}
\hline New Plant Food Eliciting Allergy & $\begin{array}{c}\text { Plant-Food-Allergy } \\
\text { Group }(\boldsymbol{n}=\mathbf{3 5})\end{array}$ & $\begin{array}{c}\text { Non-Plant-Food-Allergy } \\
\text { Group }(\boldsymbol{n}=\mathbf{5})\end{array}$ \\
\hline Rosacea $/$ Prunoideae fruit & 7 & 2 \\
\hline Rosacea / Pomoideae fruit & 3 & 0 \\
\hline Nuts & 7 & 0 \\
\hline Vegetables & 4 & 0 \\
\hline Cereals & 2 & 0 \\
\hline Legumes & 1 & 2 \\
\hline Seed & 1 & 0 \\
\hline Rosaceae/Prunoideae fruit \& nuts & 5 & 0 \\
\hline Nuts \& vegetables & 3 & 0 \\
\hline Nuts \& legumes & 1 &
\end{tabular}

Patients from this group had a mean age of 26.9 years (range 2 to 61 years) and were predominantly female $(60 \%)$. Sensitization to common allergens was present in $91.43 \%$ of the patients; $85.7 \%$ of the patients had associated rhinitis while $62.8 \%$ presented asthma. Sensitization to profilin was $31.4 \%$ and $17.1 \%$ were sensitized to PR-10. Nineteen patients received grass pollen immunotherapy and none of them to birch pollen. 


\subsubsection{Non-Food-Allergy Group: Allergy to New Foods}

Five out of 38 patients (13.2\%; 95\% CI 6-27\%) from the non-food-allergy group, which comprised patients who had never experienced allergic reactions to any plant foods, developed allergy to new plant foods. The plant foods eliciting allergy in this subgroup were as follows: Rosacea fruits in 2 patients, nuts in 2 patients, and legumes in 1 patient. Two patients from this group developed allergy to both Rosacea fruits and nuts. The allergy symptoms in these patients were local in $60 \%$ and systemic in $40 \%$. None experienced anaphylactic reactions.

Patients from this group ranged in age from 18 to 50 years (mean age 31.4 years), with a higher prevalence of females $(60 \%)$. Sensitization to common allergens was present in $100 \%$ of the patients. Rhinitis and asthma were also prevalent comorbidities $(80 \%$ and $60 \%$ of the patients, respectively). Profilin sensitization was not found in any patients and 2 patients were sensitized to PR-10 family protein (40\%). Three patients received grass pollen immunotherapy and none of them to birch pollen.

\section{Discussion}

The present study focuses on the development of allergy to new plant foods among nsLTP-sensitized patients. We consider this unresolved issue to be a key point in the management of nsLTP-allergic patients. Our results reveal that $31 \%$ of nsLTP-allergic patients became allergic to new plant foods that had been tolerated at the time of diagnosis. We also found that, after 10 years, $13 \%$ of patients simply sensitized to nsLTP developed plant-food allergy.

This is a real-life study based on clinical allergy practice. Ten years following diagnosis, a telephone interview was conducted to determine whether patients developed allergies to new plant foods. Real-life studies and the results of the telephone interviews have both advantages and disadvantages which should be considered when interpreting these results. However, we found the results to be valuable as they provide interesting information on the development of allergy to new plant foods, both among patients with nsLTP allergy and among nsLTP-sensitized subjects who have never been allergic to plant foods (latent atopy).

To our knowledge, the report by Asero et al. [19] is the only study designed to evaluate the development of new food allergies in the follow-up of patients allergic to nsLTP. The results of our study, in which $31 \%$ of patients developed new plant-food allergies, are in agreement with those of Asero et al. (27\%; 18/67 patients), which reinforces the results of both.

A literature search revealed no previous studies addressing the development of plantfood allergy among nsLTP-sensitized patients without previous plant-food allergy. We found that allergy to new plant foods among patients without previous plant-food allergy was not only less frequent, but also less severe, as no patients in the sensitized group had anaphylactic reactions. These data support current recommendations indicating that patients who experienced systemic reactions should always carry auto-injectable adrenaline with them.

Another finding of our study, and one that is found throughout the literature on nsLTP allergy, is that rosaceous fruits and nuts are the foods most frequently responsible for nsLTP allergic reactions $[14,19,20]$, even when discussing new plant-food allergies in the evolution of these patients. We consider this issue relevant, as clinicians should not restrict all nsLTP-allergenic foods in the same way, but rather prioritize the most frequently involved foods when an avoidance diet is necessary.

We also found that sensitization to profilin and PR-10 allergens appears to decrease the risk of severe reactions [21,22], and that nsLTP-specific IgE levels do not predict the occurrence of new plant-food allergy [23], which is consistent with data published in multiple studies.

Asero et al. [19] provided useful recommendations for the management of patients with nsLTP-related food allergy, which we support fully. In addition to these recommendations, we believe nsLTP-allergic patients should undergo risk stratification, as this would 
allow for tailored management of the heterogeneous and highly variable population of patients with this type of allergy. Specifically, our findings lead us to recommend the following:

- $\quad$ Patients should avoid plant foods that provoke allergic reactions after an allergy study based on anamnesis, skin testing, and/or determination of specific IgE and challenge tests when necessary;

- $\quad$ Patients with systemic reactions should always carry self-injectable adrenaline on their person;

- Additional dietary restrictions should be based on patient risk stratification, as it is impossible to predict severity and/or allergy to new plant foods. In our opinion, key points to stratify the risk of the nsLTP-allergic patients are those appearing in Table 5. Thus, for patients who have developed a systemic reaction to peach peel but who tolerate other foods (even peach pulp), it would be sufficient to avoid peach peel and take self-injectable adrenaline. However, when traveling to the mountains, the countryside, or other remote locales, they should strictly avoid foods related to the nsLTP allergy and be vigilant with NSAIDs and other cofactors, since accessibility to emergency services may be limited and their quality of life would not be significantly altered by such a one-off situation. This is an example of how allergy-management recommendations should be adapted depending on risk stratification.

Table 5. Risk stratification of nsLTP-allergic patients.

\begin{tabular}{ll}
\hline \multicolumn{1}{l}{ Key Points. } \\
\hline- & Severity of previous reactions \\
\hline- & New foods most frequently implicated \\
\hline- & Accessibility of emergency services \\
\hline- & Sensitivity to PR-10 and profilin \\
\hline- & Cofactors \\
\hline- & Quality of life \\
\hline
\end{tabular}

\section{Conclusions}

In summary, one-third of nsLTP-allergic patients developed allergy to novel plant foods, while one-tenth of nsLTP-sensitized patients without food allergy eventually developed reactions to novel plant foods, which were milder. Finally, risk stratification should be a cornerstone of individualized management for highly varied patients with nsLTP allergy.

Author Contributions: Conceptualization, D.B., E.N.-B., C.P.-V., V.E. and J.C.-H.; methodology, D.B., A.G.-L., C.V.-V., E.N.-B., S.F.-B., M.D.I.H.G.; software D.B. and J.C.-H.; validation, D.B., A.G.-L., C.V.-V., E.N.-B., S.F.-B., M.D.1.H.G., C.P.-V., V.E. and J.C.-H.; formal analysis, D.B., E.N.-B., C.P.-V., V.E. and J.C.-H.; in V.E. stigation, D.B., E.N.-B., C.P.-V., V.E. and J.C.-H.; writing-original draft preparation, D.B., E.N.-B. and J.C.-H.; writing-review and editing, D.B., A.G.-L., C.V.-V., E.N.-B., S.F.-B., M.D.I.H.G., C.P.-V., V.E. and J.C.-H.; supervision, C.P.-V., V.E. and J.C.-H.; funding acquisition, V.E. and J.C.-H. All authors have read and agreed to the published version of the manuscript.

Funding: This work was supported by grants from Instituto de Salud Carlos III co-founded by FEDER funds for the Thematic Networks and Co-operative Research Centers, ARADyAL RD16/0006/0013 and PI18/00348. Also supported by the SEAIC (19_A08) and by Comunidad de Madrid_P2018/BAAA4574. Betancor D is supported by Rio Hortega Research Contract.

Institutional Review Board Statement: The study was conducted according to the guidelines of the Declaration of Helsinki, and approved by Fundación Jiménez Díaz Ethics Committee.

Informed Consent Statement: Informed consent was obtained from all subjects involved in the study.

Acknowledgments: Oliver Shaw (IIS-FJD) for editorial support. 
Conflicts of Interest: The authors declare no conflict of interest.

\section{References}

1. Lyons, S.A.; Burney, P.G.J.; Ballmer-Weber, B.K.; Fernandez-Rivas, M.; Barreales, L.; Clausen, M.; Dubakiene, R.; Fernandez-Perez, C.; Fritsche, P.; Jedrzejczak-Czechowicz, M.; et al. Food Allergy in Adults: Substantial Variation in Prevalence and Causative Foods Across Europe. J. Allergy Clin. Immunol. Pract. 2019, 7, 1920-1928. [CrossRef]

2. Bogas, G.; Muñoz-Cano, R.; Mayorga, C.; Casas, R.; Bartra, J.; Pérez, N.; Pascal, M.; Palomares, F.; Torres, M.J.; Gómez, F. Phenotyping peach-allergic patients sensitized to lipid transfer protein and analysing severity biomarkers. Allergy 2020, 75, 3228-3236. [CrossRef]

3. Martín-Pedraza, L.; Mayorga, C.; Gómez, F.; Bueno-Díaz, C.; Blanca-López, N.; González, M.; Martinez-Blanco, M.; CuestaHerranz, J.; Molina, E.; Villalba, M.; et al. IgE-reactivity pattern of tomato seed and peel nonspecific Lipid-Transfer Proteins after in vitro gastrointestinal digestion. Agric. Food Chem. 2021, 69, 3511-3518. [CrossRef]

4. Skypala, I.J.; Bartra, J.; Ebo, D.G.; Faber, M.A.; Fernández-Rivas, M.; Gomez, F.; Luengo, O.; Till, S.J.; Asero, R.; Barber, D.; et al. The diagnosis and management of allergic reactions in patients sensitized to non-specific lipid transfer proteins. Allergy 2021. [CrossRef]

5. Vereda, A.; van Hage, M.; Ahlstedt, S.; Ibañez, M.D.; Cuesta-Herranz, J.; van Odijk, J.; Wickman, M.; Sampson, H.A. Peanut allergy: Clinical and immunologic differences among patients from 3 different geographic regions. J. Allergy Clin. Immunol. 2011, 127, 603-607. [CrossRef]

6. Haroun-Díaz, E.; Azofra, J.; González-Mancebo, E.; Heras, M.D.L.; Pastor-Vargas, C.; Esteban, V.; Villalba, M.; Díaz-Perales, A.; Cuesta-Herranz, J. Nut Allergy in Two Different Areas of Spain: Differences in Clinical and Molecular Pattern. Nutrients 2017, 9, 909. [CrossRef]

7. Mothes-Luksch, N.; Raith, M.; Stingl, G.; Focke-Tejkl, M.; Razzazi-Fazeli, E.; Zieglmayer, R.; Wöhrl, S.; Swoboda, I. Pru p 3, a marker allergen for lipid transfer protein sensitization also in Central Europe. Allergy 2017, 72, 1415-1418. [CrossRef]

8. Asero, R.; Antonicelli, L.; Arena, A.; Bommarito, L.; Caruso, B.; Colombo, G.; Crivellaro, M.; de Carli, M.; Della Torre, E.; Della Torre, F.; et al. Causes of food-induced anaphylaxis in Italian adults: A mul-ti-centre study. Int. Arch. Allergy Immunol. 2009, 150, 271-277. [CrossRef]

9. Cuesta-Herranz, J.; Lázaro, M.; Figueredo, E.; Igea, J.M.; Umpiérrez, A.; De-Las-Heras, M. Allergy to plant-derived fresh foods in a birch- and ragweed-free area. Clin. Exp. Allergy 2000, 30, 1411-1416. [CrossRef]

10. Murad, A.; Katelaris, C.H.; Baumgart, K. A case study of apple seed and grape allergy with sensitisation to nonspecific lipid transfer protein. Asia Pac. Allergy 2016, 6, 129-132. [CrossRef]

11. Gao, Z.-S.; Yang, Z.; Wu, S.-D.; Wang, H.-Y.; Liu, M.-L.; Mao, W.-L.; Wang, J.; Gadermaier, G.; Ferreira, F.; Zheng, M.; et al. Peach allergy in China: A dominant role for mugwort pollen lipid transfer protein as a primary sensitizer. J. Allergy Clin. Immunol. 2013, 131, 224-226.e3. [CrossRef]

12. Faber, M.A.; van Gasse, A.L.; Decuyper, I.I.; Uyttebroek, A.; Sabato, V.; Hagendorens, M.M.; Bridts, C.H.; de Clerck, L.S.; Fernandez-Rivas, M.; Pascal, M.; et al. IgE-reactivity profiles to nonspecific lipid transfer proteins in a northwestern Eu-ropean country. J. Allergy Clin. Immunol. 2017, 139, 679-682. [CrossRef] [PubMed]

13. Pascal, M.; Cano, R.M.; Reina, Z.; Palacín, A.; Vilella, R.; Picado, C.; Juan, M.; Sánchez-López, J.; Rueda, M.; Salcedo, G.; et al. Lipid transfer protein syndrome: Clinical pattern, cofactor effect and profile of molecular sensitization to plant-foods and pollens. Clin. Exp. Allergy 2012, 42, 1529-1539. [CrossRef]

14. Du Toit, G.; Roberts, G.; Sayre, P.H.; Bahnson, H.T.; Radulovic, S.; Santos, A.F.; Brough, H.A.; Phippard, D.; Basting, M.; Feeney, M.; et al. LEAP Study Team. Randomized trial of peanut consumption in infants at risk for peanut allergy. N. Engl. J. Med. 2015, 372, 803-813. [CrossRef]

15. Anagnostou, K.; Islam, S.; King, Y.; Foley, L.; Pasea, L.; Bond, S.; Palmer, C.; Deighton, J.; Ewan, P.; Clark, A. Assessing the efficacy of oral immunotherapy for the desensitisation of peanut allergy in children (STOP II): A phase 2 randomised controlled trial. Lancet 2014, 383, 1297-1304. [CrossRef]

16. Gomez, F.; Bogas, G.; Gonzalez, M.; Campo, P.; Salas, M.; Diaz-Perales, A.; Rodriguez, M.J.; Prieto, A.; Barber, D.; Blanca, M.; et al. The clinical and immunological efects of Pru p 3 sublingual immunotherapy on peach and peanut allergy in patients with systemic reactions. Clin. Exp. Allergy 2017, 47, 339-350. [CrossRef]

17. González Pérez, A.; Carbonell Martínez, A.; Escudero Pastor, A.I.; Navarro Garrido, C.; Miralles López, J.C. Pru p 3 oral immuno-therapy eficacy, induced immunological changes and quality of life improvement in patients with LTP syndrome. Clin. Transl. Allergy 2020, 10, 20. [CrossRef]

18. Beitia, J.M.; Castro, A.V.; Cárdenas, R.; Peña-Arellano, M.I. Pru p 3 Sublingual Immunotherapy in Patients with Lipid Transfer Protein Syndrome: Is It Worth? Int. Arch. Allergy Immunol. 2021, 182, 447-454. [CrossRef] [PubMed]

19. Asero, R.; Piantanida, M.; Pravettoni, V. Allergy to LTP: To eat or not to eat sensitizing foods? A follow-up study. Eur. Ann. Allergy Clin. Immunol. 2018, 50, 156. [CrossRef] [PubMed]

20. Scala, E.; Till, S.J.; Asero, R.; Abeni, D.; Guerra, E.C.; Pirrotta, L.; Paganelli, R.; Pomponi, D.; Giani, M.; de Pità, O.; et al. Lipid transfer protein sensitization: Reactivity profiles and clinical risk assessment in an Italian cohort. Allergy 2015, 70, 933-943. [CrossRef] [PubMed] 
21. Pastorello, E.A.C.; Farioli, L.; Pravettoni, V.; Scibilia, J.; Mascheri, A.; Borgonovo, L.; Piantanida, M.; Primavesi, L.; Stafylaraki, C.; Pasqualetti, S.; et al. Pru p 3-sensitised Italian peach-allergic patients are less likely to develop severe symptoms when also presenting IgE antibodies to Pru p 1 and Pru p 4. Int. Arch. Allergy Immunol. 2011, 156, 362-372. [CrossRef]

22. Scala, E.D.; Abeni, D.; Guerra, E.C.; Locanto, M.; Pirrotta, L.; Meneguzzi, G.; Giani, M.; Asero, R. Cosensitization to profilin is associat-ed with less severe reactions to foods in nsLTPs and storage proteins reactors and with less severe respiratory allergy. Allergy 2018, 73, 1921-1923. [CrossRef]

23. Pastorello, E.A.; Farioli, L.; Pravettoni, V.; Robino, A.M.; Scibilia, J.; Fortunato, D.; Conti, A.; Borgonovo, L.; Bengtsson, A.; Ortolani, C. Lipid transfer protein and vicilin are important walnut allergens in patients not allergic to pollen. J. Allergy Clin. Immunol. 2004, 114, 908-914. [CrossRef] 